\title{
Suggested Strategies in Water Treatment by Using Situ Pressure in Reverse Osmosis
}

\author{
Susan Norouzi \\ Fatemeh Zahra Campus, Farhangian University, Esfahan, Iran \\ Email: norouzi48@yahoo.com \\ Received 1 April 2015; accepted 23 May 2015; published 26 May 2015 \\ Copyright (C) 2015 by author and Scientific Research Publishing Inc. \\ This work is licensed under the Creative Commons Attribution International License (CC BY). \\ http://creativecommons.org/licenses/by/4.0/ \\ c) (i) Open Access
}

\begin{abstract}
Nowadays desalination is one of the main resources to obtain water in many areas. The most advanced method for water filtration is reverse osmosis. In this system, water is injected into semimembranes by using power pumping, and its salt water is taken away from the solution. This paper has tried to offer guidelines to use the pressure created in situ of harvesting water, instead of utilizing power pump, which produces the necessary pressure for the reverse osmosis. These guidelines have been divided into 2 main groups: Using the created natural pressure, and the other way is using the pressures that are caused by the constructions built for harvesting water.
\end{abstract}

\section{Keywords}

Strategies, Water, Treatment, Reverse Osmosis, In Situ

\section{Introduction}

In this century, the most crucial problem afflicting people around the world is global water scarcity. The rapid growth in population has resulted in greater demand on the quantity of drinking water, leading to catastrophic water shortage in arid and water-stressed region areas. It is projected that by year 2030, the global needs of water would increase to 6900 billion $\mathrm{m}^{3}$ from the current 4500 billion $\mathrm{m}^{3}$. So, about $53 \%$ increase for drinking water is needed by year 2030. The global installed desalination capacity by water sources and the use of seawater as feed brine have contributed more than half of the total capacity produced worldwide. Desalination is necessary in arid countries and in cases where good-quality water is required for industrial purposes and fresh water is not available [1]. During the past 30 years, reverse osmosis (RO) is increasingly used in seawater and brackish water desalination, water treatment and wastewater reclamation due to the superior and stable quality of the water produced and an $80 \%$ share in the total number of desalination plants installed worldwide [2]. In the United States of America, which has allocated over $17 \%$ of the world desalination of salinity, reverse osmosis is the 
dominant method in desalting [3]. Spain and Italy hold the majority of the European desalination capacity, with each country holding $2.6 \%$ of world production capacity; $69 \%$ of desalination plants in Spain use RO technology, while only $20 \%$ of plants in Italy use RO, Japan holds 3.7\% of global production [4] and has been using seawater RO technology since 1974. Countries in South America, such as Chile, have recently implemented large desalination plants [5], and Australia has been battling a water crisis with new RO installations from Melbourne to the Gold Coast [6]. Membranous process probably turns saltwater into fresh one. One of the most minuscule membranes in separating process is osmosis membranes. In reverse osmosis, the water moves from higher concentration to the lower one due to the pressure entering the salt water, furthermore, water moves against the Salts concentration gradients and natural direction osmosis. Pure water passes through the membrane, thus, salt remains in the other side of the membrane. In this process, in addition to salt ions, the other substances in water such as suspended particles, viruses, minerals, organic matter and microbes are separated from the water. In this method, pressure must be increased by rising the amount of solute in water. Thus, the required pressure for desalination is 10 to 15 bars for the brackish water and about 54 to 80 bars for seawater [7]. Therefore, the purpose of this research is utilizing the pressure, which is available at harvested areas. Moreover, based on the obtained results, the most efficient and practical option for the regional and climatic conditions is suggested to be a small step to improve water crisis.

\section{Materials and Strategies}

In reverse osmosis systems, water is injected inside the semi-permeable membranes with tiny pores (about 42 microns) by using power pumps. These pores can prevent the molecules, which are larger than water molecules from passing through, so the water that is almost pure flows from one side, and the condensed water (high salt) flows on the other side (Figure 1). An RO membrane is operated by achieving a hydrostatic pressure greater than the osmotic pressure of the solution. The positive difference in pressure creates a chemical potential difference (concentration gradient) across the membrane that drives the liquid through the membrane against the natural direction of osmosis (the movement of water molecules from an area of high concentration to an area of low concentration), while the salts are retained and concentrated on the influent surface of the membrane [8]. A reverse osmosis device simply consists of the following parts:

a-A semi-permeable membrane that lets water molecules pass through

b-A control valve in the track of liquid concentrates (brine) to control the degree of concentration

c-A water pump to provide the necessary pressure

In terms of location, water treatment is classified in two categories situ and in situ. In-Situ Treatment methods is performed in place of contamination and in Ex-Situ treatment is a method that water extracts in the site and refines outside the location. One of the most common methods of treating is the pumping system in place. In this system, after pumping water from wells, using methods such as reverse osmosis is treated. However, this process requires advanced equipment, skilled operators and expended so much energy that leads to the purification process becomes expensive. However, in situ treatment is more economical and they have no complexities. But the well water is still untreated in situ [10]. In this paper, the strategies are briefly introduced. For the in situ filtration with reverse osmosis and offer some guidelines to create the necessary pressure of reverse osmosis

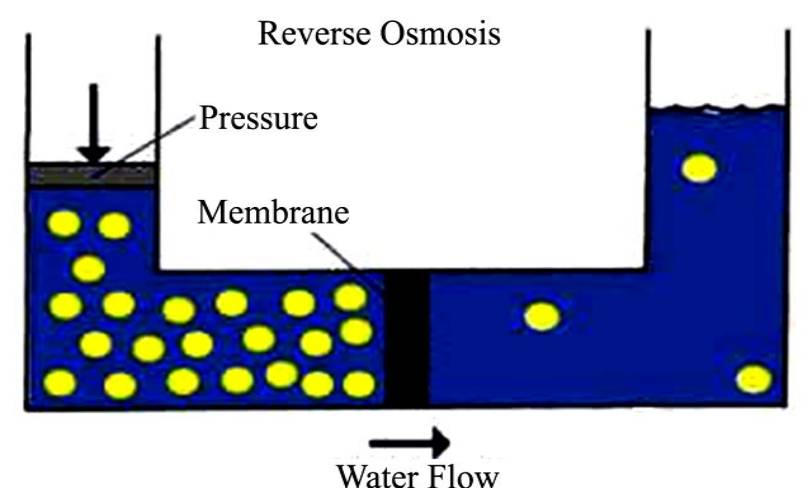

Figure 1. Reverse osmosis process [9]. 
without pumps. In this method the existing pressure, that is naturally created or by using devices, is used in those areas to obtain the necessary reverse osmosis.

\subsection{The Pressure Created by Water Pumps}

A semi-permeable membrane (A) is placed in the path of a water suction to provide the pressure for reverse osmosis (Figure 2).

\subsection{The Pressure Created by Dams}

An Increase in water height and the pressure created with the flow of water can be used in water purification in reverse osmosis method. Here special membrane can be contrived in the path of water before it arrives the generator (Figure 3).

\subsection{The Use of Natural Pressure}

\subsubsection{The Use of Pressure in Confined Aquifers or Artesian Groundwater}

When there is water in confined aquifers (Figure 4), using natural pressure in these layers can be fruitful for harvesting water in reverse Osmosis method.

\subsubsection{The Use of Pressure Created by Sea Water}

In this method, according to Figure 5 small Channels were dug inside the salt water source (the sea, $\cdots$ ) and water is transmitted there. As shown in Figure 5 small channels (B) are made in the vicinity of saline water source (A) and water is transported inside the channel. The seawater with natural pressure passes through the filter,

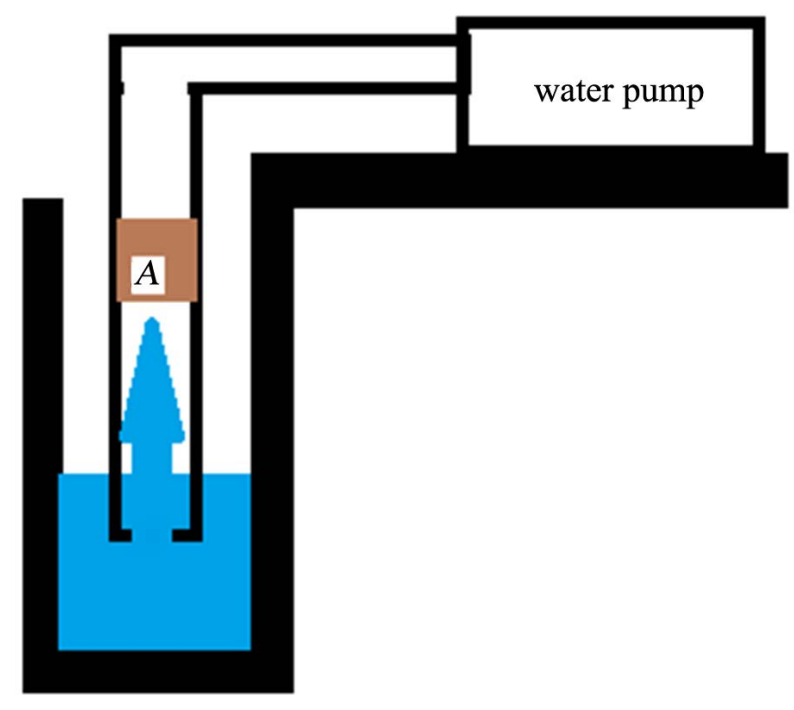

Figure 2. The use of the pressure caused by pumping water.

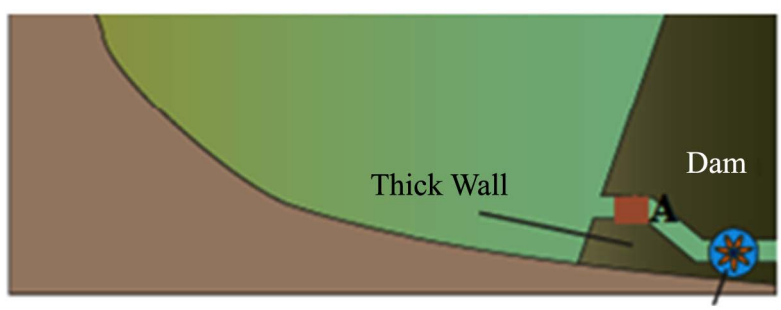

Generator

Figure 3. The use of the pressure created dams for water purification in reverse osmosis. 


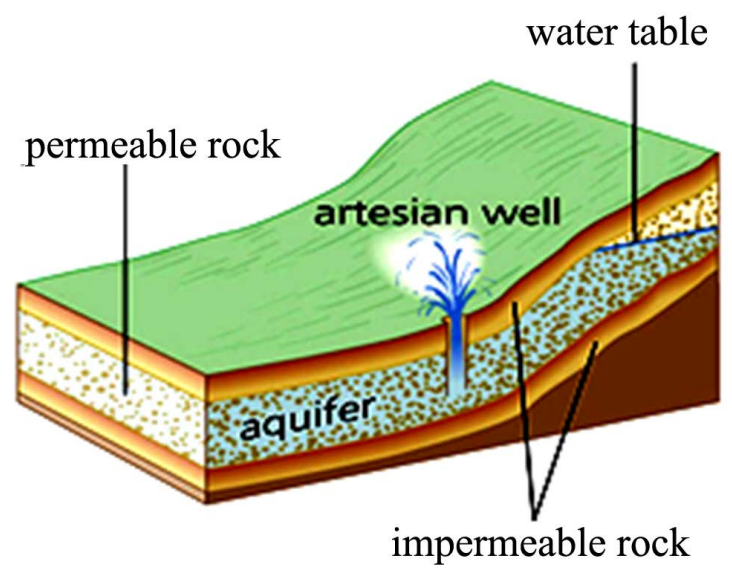

Figure 4. Confined aquifers or artesian groundwater.

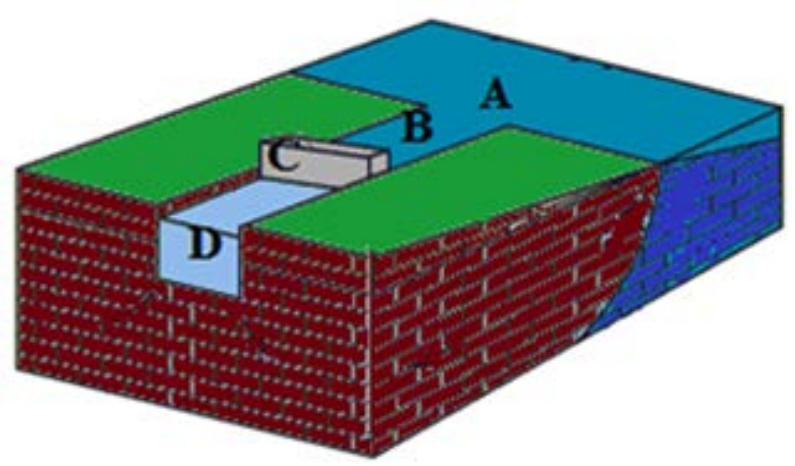

Figure 5. The small channels in the way of the water of the sea.

which has been embedded in the walls of the channel (C). Sometimes it can provide the pressure required for the reverse osmosis process; therefore, fresh water can be picked out from the membrane (D).

A-The saline water source

B-The small, deep channels

C-The wall in the path of channel

D-The water passing through the membrane embedded in channel walls

\subsection{The Pressure Caused by Creating Height}

The more the depth in the liquid, the more the pressure. The created pressure can be used for water purification in the reverse osmosis method. By considering the density of the brine pressure the required height to make the pressure is reduced. By using the formula for Liquid Pressure, the required height to create the necessary pressure in reverse osmosis is to be calculated. (If you go down10 meters, the pressure increases by 14.7 psi (1 bar))

$$
\begin{aligned}
& \mathrm{P}=\mathrm{P} 0+\text { pgh } \\
& \mathrm{P}=\text { Final Pressure } \\
& \mathrm{P} 0=\text { Initial Pressure } \\
& \mathrm{p}=\text { density of liquid } \\
& \mathrm{g}=\text { Acceleration of gravity } \\
& \mathrm{h}=\text { The height of the liquid } \\
& \text { Creating height can be done in several ways: }
\end{aligned}
$$

\subsubsection{Using High Pipes}

In this method, as shown in Figure 6 the salty water is pumped (B) from tank E into a long tube A, whose end is 


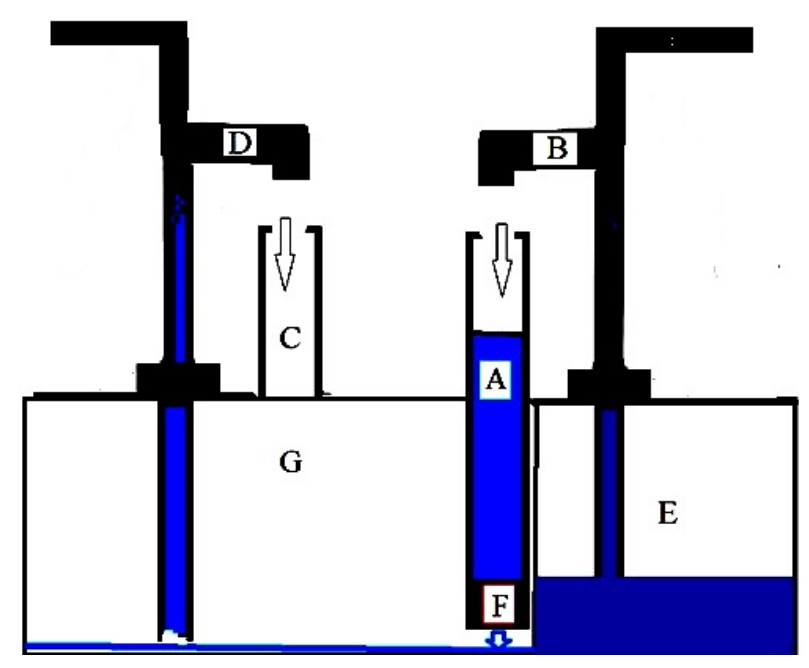

Figure 6. Using high pipes.

installed a semi-permeable membrane. Next, the water is collected in tank G, which is separated by a wall from tank E. The height of the pipe is designed based on the pressure required for reverse osmosis. Due to the pressure caused by the height of the liquid, reverse osmosis occurs and water is collected in tank G.
A) A high Pipe containing brine
B) A saltwater Transferor pump
C) A fresh water tank
D) A fresh water Transferor pump
E) Saline water source
F) A Semi Permeable Membrane
G) Collected fresh water

\subsubsection{The Use of Underground Dams}

When the groundwater passes through the impermeable layer, with the construction of an underground dam, against the flow and rising the water level, the required pressure can be created to establish RO pressure (Figure 7).
A) Under groundwater
B) Impermeable layers
C) Underground dams
D) Water Well
E) Surface Earth

By embedding filters in the underground dams and sending water through the filters, fresh water can be harvested from the other side (Figure 8).

\section{Conclusion}

There will be problems when applying the proposed methods, but because the treatment is done in situ, there won't be the problems existing in construction of water treatment facilities, including the transfer of salt water. It also reduces some problems such as excretion of saline waste, which is one of the problems of the method of de-salinization. However in the methods presented, water flow is connected to the main water source furthermore, their concentration of residual and deposition of calcium carbonate and calcium sulfate decreases because the water flow is connected to the main source of water. Another advantage of this method is the use of it, in the areas of the wells with salt water.

\section{Suggestion}

Nowadays scientists are seeking to explore freshwater resources beneath the sea [12]. Thus, what suggested in 


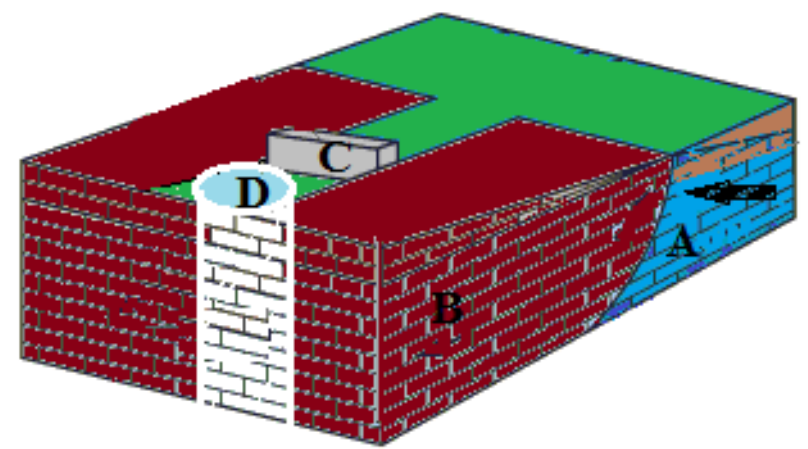

Figure 7. The use of underground dams to increase water height to be used in reverse osmosis.

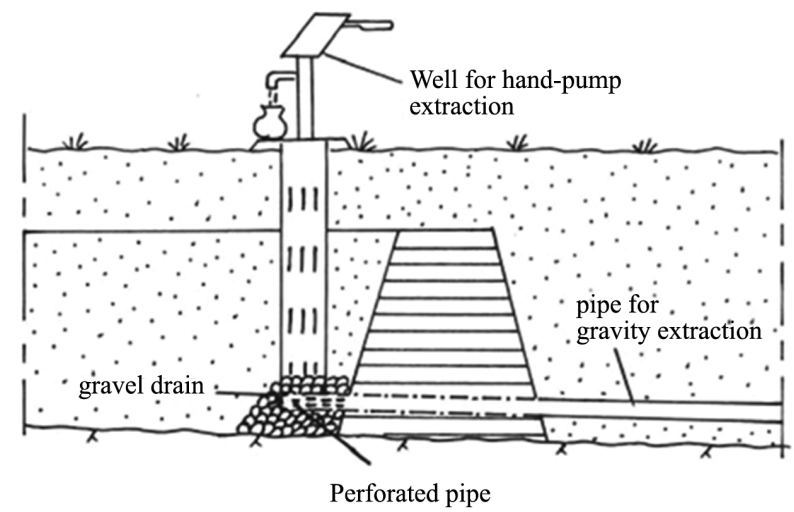

Figure 8. Water extraction from a sub-surface dam [11].

this paper is to study the effectiveness of the type and thickness of sea floor sediments in RO phenomenon in order to harvest fresh water underneath sea floor.

\section{References}

[1] Abdel-Aal, E.A. and Farid, M.E. (2015) Desalination of Red Sea Water Using Both Electro Dialysis and Reverse Osmosis as Complementary Methods. Egyptian Journal of Petroleum, In Press. http://dx.doi.org/10.1016/j.ejpe.2015.02.007

[2] Koltuniewicz, A.B. and Drioli, E. (2008) Membrane in Clean Technologies: Theory and Practice, Vol. 1. Wiley-VCH, Berlin.

[3] Gleick, P.H. (2006) The Biennial Report on Freshwater Resources. The World's Water, Island Press, Chicago.

[4] Miller, J.E. (2003) Review of Water Resources and Desalination Technologies. Sandia National Laboratories. http://www.prod.sandia.gov/cgi-bin/techlib/access-control.pl

[5] Petry, M., Sanz, M.A., Langlais, C., Bonnelye, V., Durand, J.P., Guevara, D., Nardes, W.M. and Saemi, C.H. (2007) The El Coloso (Chile) Reverse Osmosis Plant. Desalination, 203, 141-152. http://dx.doi.org/10.1016/j.desal.2006.05.007

[6] Veolia (2007) Veolia Eau Wins a Large Desalination Contract in Sydney, Australia. Veolia Eau. http://www.veoliaenvironnement.com/fr/presse/20070718,dessalementaustralie.aspx (In French)

[7] Spiegler, K.S. and El-Sayed, Y.M. (1994) A Desalination Primer. Balaban Desalination Publications, Santa MariaImbaro, Italy.

[8] Greenleea, L.F., Lawlerb, D.F., Freemana, B.D., Marrot, B. and Moulin, P. (2009) Reverse Osmosis Desalination: Water Sources, Technology, and Today's Challenges. Water Research, 43, 2317-2348.

[9] American Water Works Association, Membrane Residuals Management Subcommittee (2004) Current Perspectives on Residuals Management for Desalting Membranes. Journal of American Water Works Association, 96, 73-87.

[10] Amiry, M. and Hekmatzadeh, A. (2014) Provide a New Method of Treating the Water from Underground Sources to 
Help Active Permeable Wall. Eighth National Congress on Civil Engineering, Faculty of Engineering, Babol.

[11] Nilsson, A. (1988) Ground Water Dams for Small-Scale Water Supply. IT Publication, London.

[12] Post, V.E.A., Groen, J., Kooi, H., Person, M., Ge, S. and Edmunds, W.M. (2013) Offshore Fresh Groundwater Reserves as a Global Phenomenon. Nature, 504, 71-78. 